\title{
Acción antimicrobiana de algunos antibióticos extraídos de hongos superiores
}

Por Angelina Pérez Silva

El conocimiento de substancias antagónicas producidas por organismos no data precisamente de? reciente descubrimiento de la penicilina, la estreptomicina y otras, sino que se remonta al siglo XIX. En el año de 1876 Tyndal, conocido como notable físico, describe en su OPTICAL REPORTMENT OF THE ATMOSPHERE IN RELATION TO THE PHENOMENA OF PUTREFACTION AND INFECTION una acción antagónica de una especie de Penicilium hacia el crecimiento de bacterias y atribuye esta acción una interferencia por el oxígeno.

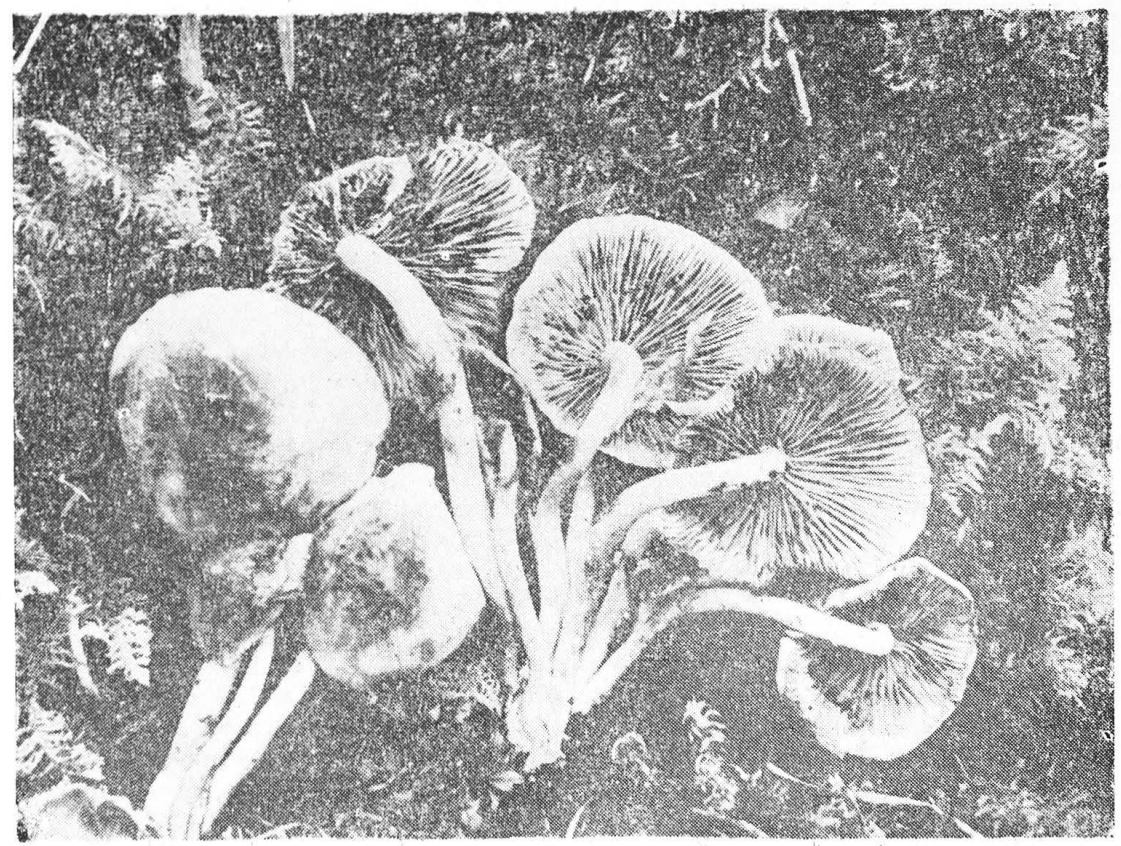

Naemataloma fasciculare mostrando laminillas.

Fot. M. Ruiz Oronoz.

Pérez-Silva A. 1959. Acción antimicrobiana de algunos antibióticos extraídos de hongos superiores. Boletín de la Sociedad Botánica de México 24: 1-13. 
Un año más tarde, en 1877, PASTEUR y JOUBERT demuestran el antagonismo bacteriano in-vitro con el bacilo del ántrax y suponen que este antagonismo se debe a la producción de alguna substancia que se di funde en el medio.

Habiendo despertado interés estas investigaciones de PASTEUR, siguieron estudios posteriores en los que se trata de modificar los medios líquidos a sólidos para observar mejor cuando un organismo elabora sustancias capaces de destruir a otros organismos, y al igual que PASTEUR. SOYKA en 1885, investiga el antagonismo bacteriano examinando la capacidad del medio en el cual un organismo ha crecido soportando el desarrollo de otras especies.

BABES, en 1885, aparentemente fué el primero en señalar que un medio sólído es mejor que un medio líquido para demostrar la inhibición microbiana, y nos indica que el desarrollo de una bacteria conocida, produce sustancias químicas que modifican el medio de cultivo, que en tales condiciones daña a otras bacterias. Este método descrito por él, para la demostración de inhibiciones sobre medios sólidos, difiere poco de los procedimientos usados en la actualidad.

En el mismo año CANTINI dice: "el hecho de que ciertas bacterias puedan destruir otros cultivos aun en gérmenes patógenos que están en contacto con ellas, nos da una idea para explorar el tratamiento de las enfermedades infecciosas".

Las investigaciones de los antibióticos fueron olvidadas por mucho tiempo hasta que, en 1929, sobresale un nuevo descubrimiento en este campo de los antibióticos por el investigador Inglés ALEXANDER FLEMING, quien descubrió que la penicilina era producida por un moho: trabajando con cepas de estafilococos, observó que algunas cajas se habían contaminado $\mathrm{y}$, además, dicha contaminación producía la lisis de las cepas estudiadas; dió a conocer su descubrimiento después de comprobar que filtrados muy diluídos de dicho moho producían inhibición y, más tarde, demostró que era una sustancia no tóxica para animales y células.

Entre las muchas propiedades de los antibióticos se busca la de la selectividad bacteriana, primeramente probada por FLEMING en sus investigaciones sobre la penicilina; en la actualidad se trata de encontrar antibióticos que inhiban tanto a gérmenes Gram positivos como a Gram negativos.

Cada día se ve más invadido este campo, en busca de nuevas sustancias antibióticas, producidas principalmente por vegetales. Hasta la fecha los antibióticos que han dado mejores resultados son los producidos por 
Actinomycetes, pero producen antibióticos diversos organismos tales como bacterias, levaduras, mohos, plantas y animales superiores, etc. Algunos antibióticos son segregados al exterior de las células y en torno a ellas; otros permanecen retenidos en las células y han de retirarse por extracción.

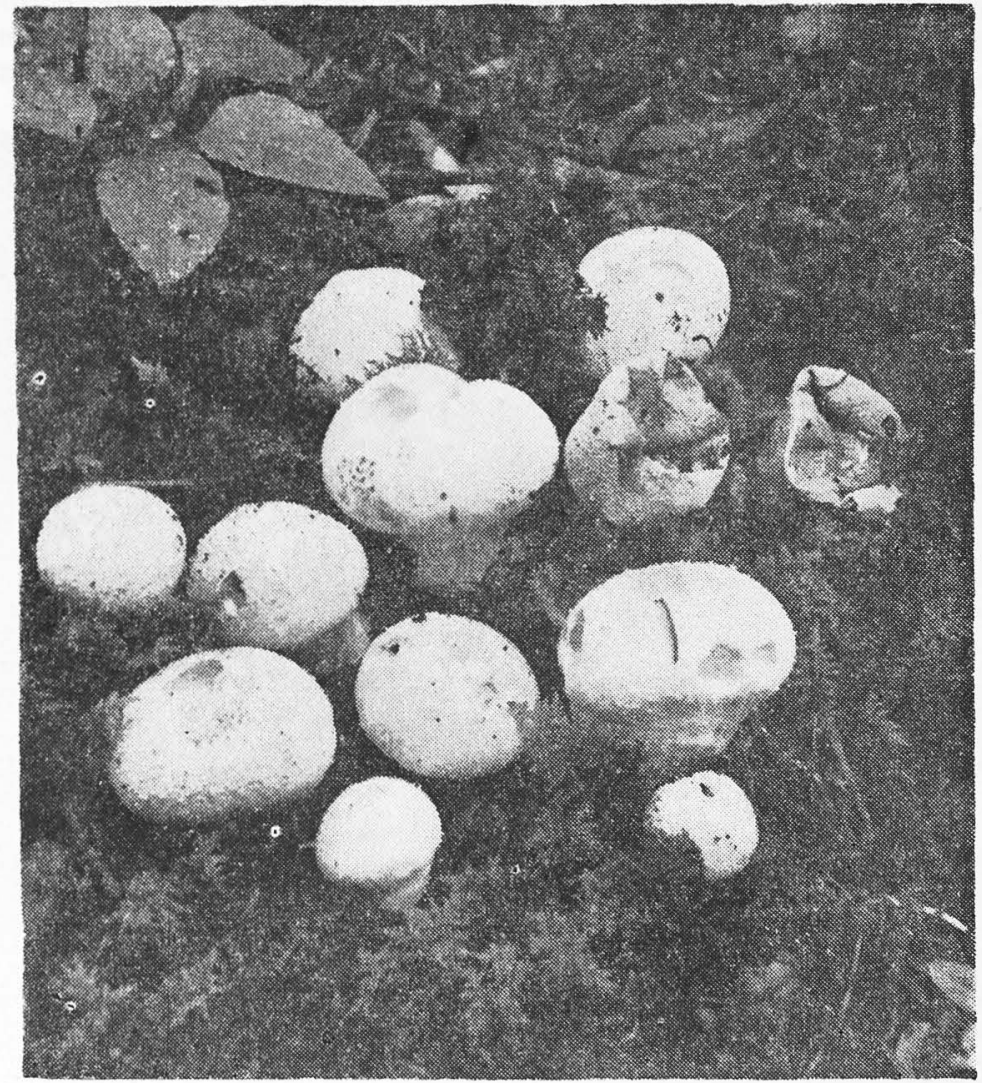

Lycoperdon perlatum.

Fot. M. Ruiz Oronoz.

Ciertos antibióticos proceden de más de un microorganismo, como sucede con las distintas penicilinas que se obtienen incorporando ciertos precursores afines al medio de cultivo o bien puede suceder que un mismo microorganismo produzca dos o más antibióticos, como es el caso de Bacillus brevis, productor de tirotricina, substancia que ha resultado ser una mezcla de gramicidina y tirocidina; Streptomyces lavendulae elabora estreptomicina, lavendulina, estreptolina y cloromicetina. 
Entre los hongos superiores, se calcula que de los Basidiomycetes se encuentran estudiados aproximadamente unas 700 especies, de las cuales alrededor de 70 dan una fuerte reacción positiva y unas 100 sólo man:fiestan una reacción débil contra $M$. pyogenes var. aureus, y $E$. coli.

Un problema importante que se presenta durante la quimioterapia y antibioticoterapia, es que los antibióticos dan lugar a cepas resistentes después de haber estado en contacto con los microorganismos; ejemplo

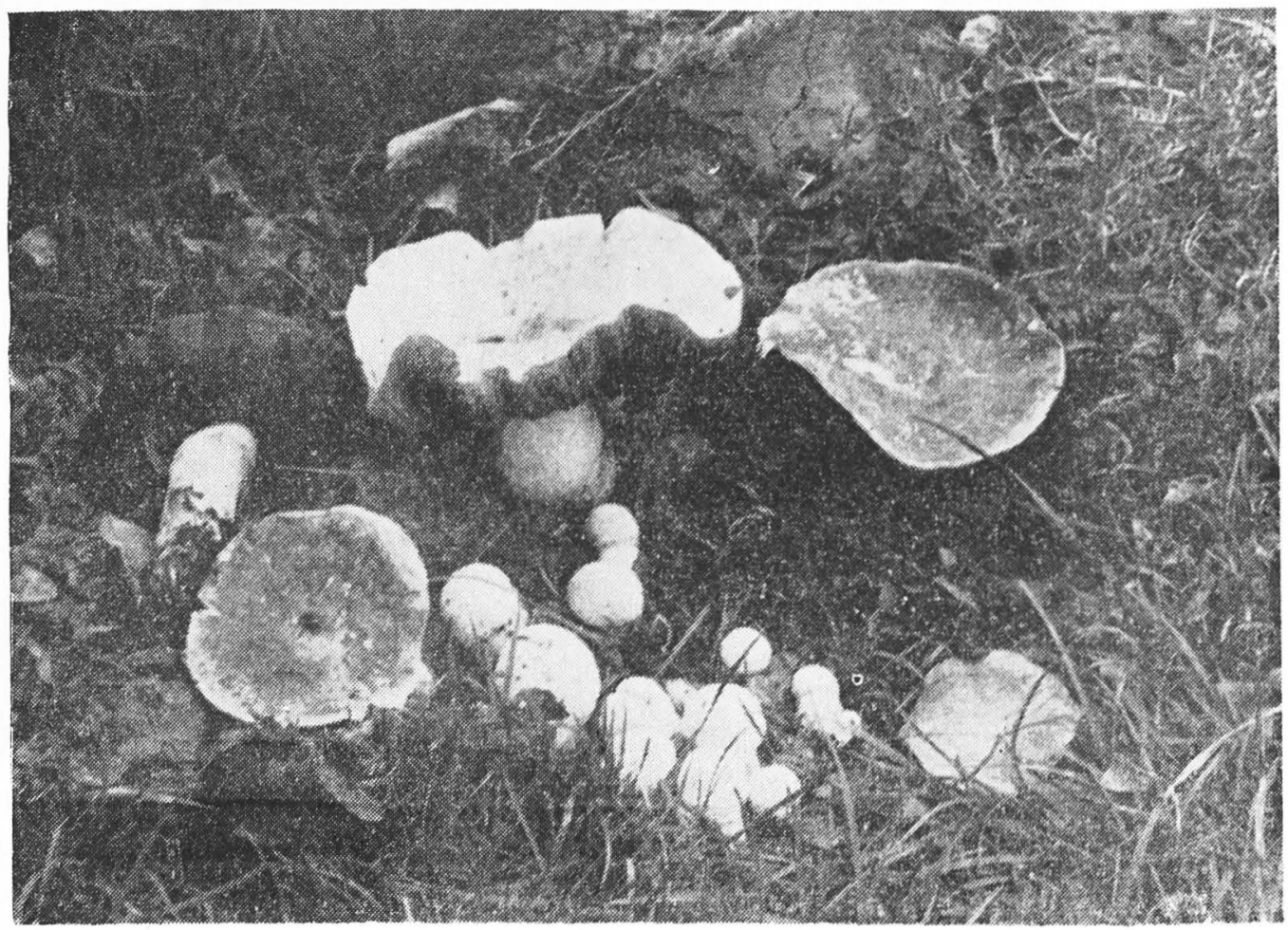

Agaricus placomyces en diferentes etapas de crecimiento.

de este caso es el de la mayoría de las bacter:as, que son los microorganismos más sensibles a los antibióticos. Esta es una de las causas por las cuales no siempre se efectúa la terapéutica con un solo antibiótico, sino que se tienen que usar combinaciones de dos o tres de ellos.

Del estudio que se hizo de 12 Basidiomycetes con el fin de encontrar substancias antagónicas, nos ocuparemos con más detalle de Lycoperdon 
perlatum, Naematoloma fasciculare y Agaricus placomyces, por ser las especies que consideramos más interesantes debido a su clara actividad antibiótica. Este estudio fué realizado en el Laboratorio de Criptogamia del Instituto de Biología de la Universidad Nacional de México.

\section{Material y Método de Estudio}

El material usado para la elaboración de este trabajo fué colectado en excursiones realizadas a los siguientes lugares: carretera a Tlamacas, Desierto de los Leones, faldas del Nevado de Toluca y Ciudad Universitaria de México, por el Dr. Manuel Ruiz Oronoz y el Biólogo Teófilo Herrera S. Cuando fué necesario se usó material del Herbario del Instituto de Biología de la U.N.A.M. La clasificación del material empleado fué hecha por el Biólogo Teófilo Herrera S. A continuación se dan a conocer los nombres de los hongos con que se trabajó.

$\begin{array}{lc}\text { GENERO Y ESPECIE } & \text { PARTE EMPLEADA } \\ \text { Agaricus placomyces } & \text { Carpoforo } \\ \text { Agaricus subrutilescens } & " \\ \text { Amanita cuesarea } & " \\ \text { Boletus edulis } & " \\ \text { Clitocybe sp. (estípite blanco) } & " \\ \text { Clitocybe sp. (estípite moreno) } & , \\ \text { Collybia sp. } & ", \\ \text { Gomphus floccosus } & " \\ \text { Laclarius deliciosus } & , \\ \text { Licoperdon perlatum } & ", \\ \text { Melanoleuca vulgaris } & , \\ \text { Naematoloma fasciculare } & \end{array}$

Los nombres de los microorganismos que se usaron para probar los extractos de los hongos, se dan a conocer a continuación:

Bacillus subtilis I.B.

Bacillus subtilis No 6633 A.T.C.C.

Micrococcus pyogenes var. aureus № 6538, A.T.C.C.

Micrococcus pyogenes var. aureus I.B.

Escherichia coli I.B.

Salmonella paratyphi A V.M.

Salmonella paratyphi $B$ V.M.

Sacharomyces carbajali No 1 M.R.O.

Sacharomyces cerevisiae No 313 M.R.O.

Crytococcus neoformans var. inocuans No 201 M.R.O.

Candida albicans No 238 M.R.O. 


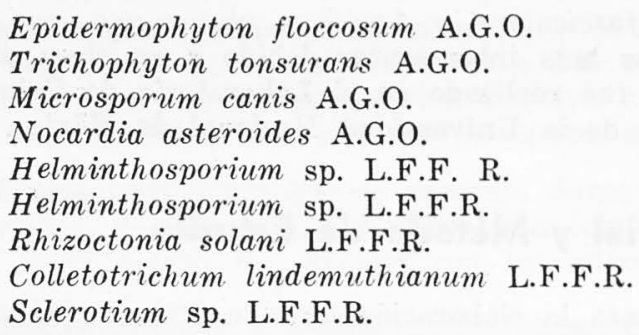

Los organismos que nos sirvieron de prueba fueron conservados en medios deshidratados de la casa Difco. Se utilizó el mismo tipo de medios para las pruebas de los antibióticos.

\section{Extracción del antibiótico}

En todos los casos se sometieron los carpoforos a la acción de diferentes solventes usando en orden progresivo: agua estéril, amortiguador $\mathrm{pH}_{6}$ cuando el medio usado para la prueba era el de la penicilina, amortiguador $\mathrm{pH}_{8}$ cuando se usaba el medio de la estreptomicina, alcohol etílico de $96^{\circ}$ y acetona.

Los hongos fueron macerados en licuadora o mortero adicionando por cada 0.5 de hongo, 5 c.c. de solvente. Obtenido el extracto, se dejaba reposar dos horas en algunos casos y en otros hasta $24 \mathrm{hrs.}$, con el objeto de extraer la mayor cantidad de substancia antagónica; después se recogía el extracto en matraces pequeños estériles filtrándolo a través de papel filtro estéril.

\section{Métodos usados}

Existen varios medios biológicos para la observación y determinación de las sustancias capaces de producir antagonismo. Entre estos métodos je pueden citar los siguientes: el de las copas de Oxford, el de De BeerSherwood o de los discos de papel, el de Waksman-Reilly o de las diluciones y estrías; el método de las estrías de Garré, el turbidimétrico, etc.

Todos estos métodos varían según el medio usado, el organismo de prueba y el tiempo de acción de la sustancia estudiada, pues cada uno presenta sus ventajas y desventajas, ya que los resultados obtenidos por un método no son siempre comparables con los obtenidos por otros métodos.

En el presente trabajo se usaron tres métodos, y debido a que no siempre se aplicaron las mismas cepas los resultados en ocasiones fueron äiferentes. 


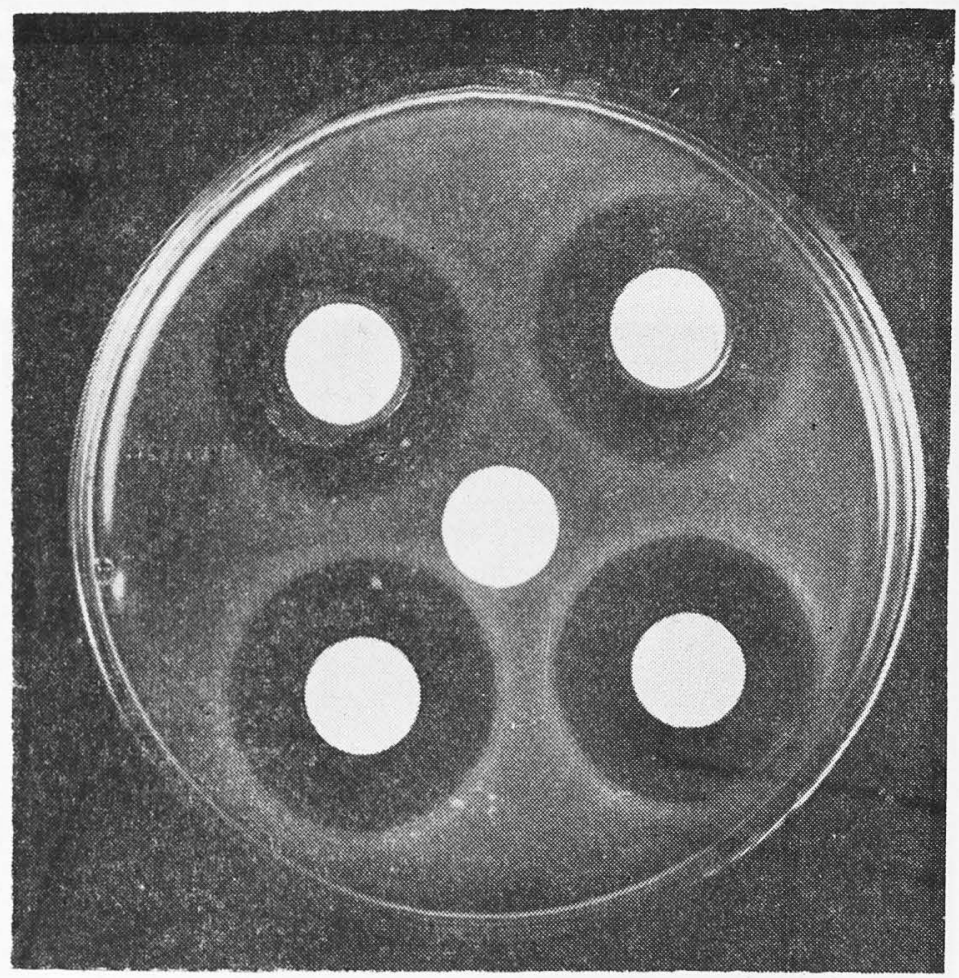

Halos de inhlbición de extracto crudo puriflcado Agaricus placomyces contra Escherichia coli. Obsérvese la contaminación.

\section{Purificación del extracto, separación y toxidad}

Con el objeto de usar extractos lo más puro que se pudiera, se procedió a purificar'os, para lo cual se emplearon dos métodos.

A.-Usando Norita A.

B.--Con un filtro de Mandler.

\section{Purificación con Norita A}

Los hongos son macerados en alcohol de $70^{\circ}$ ó $96^{\circ}$ poniendo por cada $0.5 \mathrm{gr}$. de hongo 5 c.c. de solvente, se deja reposar por espacio de 24 horas con el objeto de que quede libre la mayor cantidad de sustancia antagónica presente en el hongo; se le agrega la Norita al $1 \%$, se agita durante $30^{\prime}$, se filtra en papel y matraz estériles; el residuo se deja secar 
a temperatura ambiente durante 24 horas. Durante este proceso de sustancia antagónica queda adsorbida en la Norita A y son llevadas con el filtrado las impurezas que perturben el ensayo. Transcuridas la: 24 horas, se eluye con alcohol etílico de $96^{\circ}$ ó de $70^{\circ}$ agitándose d'urćnte $30^{\prime}$ y el carbón se separa de la elución por centrifugación durante 30'; a $1500 \mathrm{r} / \mathrm{m}$.

El extracto obtenido de esta manera se probó por el métoủo de las Copas de Oxford.

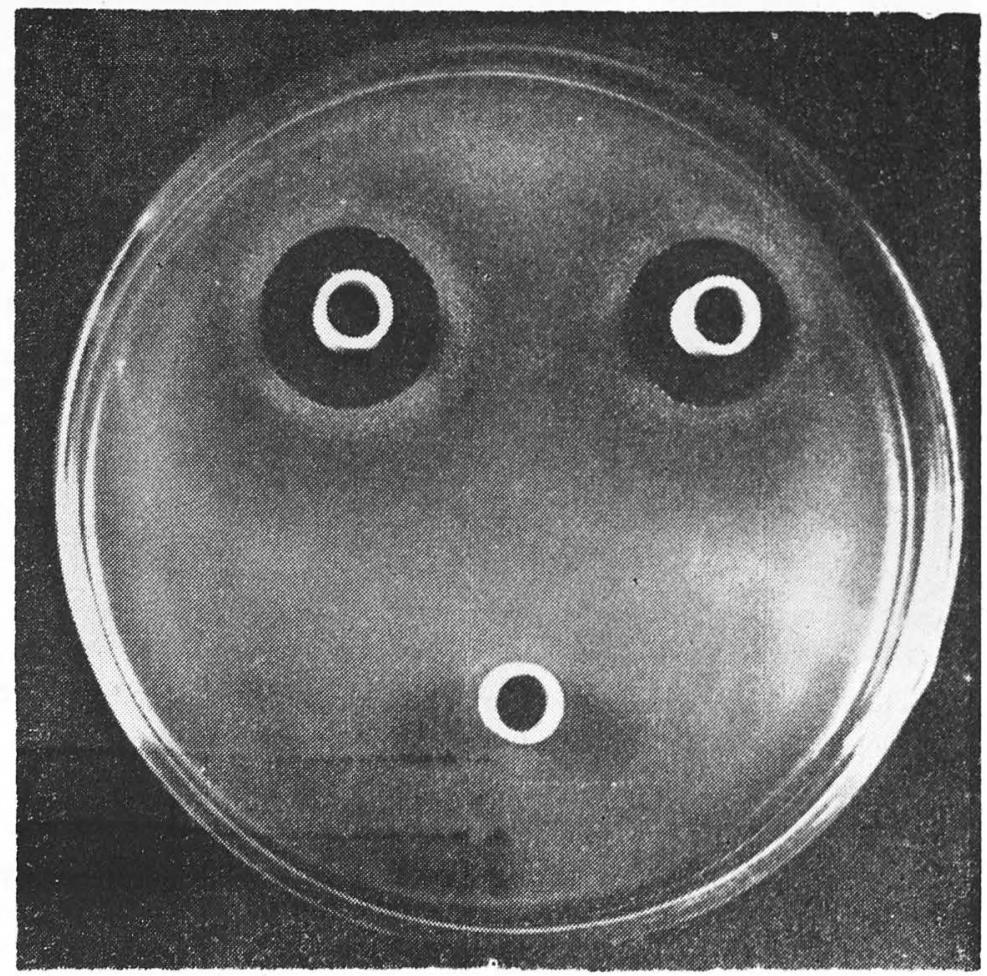

Halos de inhibación del extracto purificado de Agaricus placomyces 24 horas después de la incubación. Germinación de prueba Escherichia coli.

Durante la purificación del extracto de Naematoloma fasciculare poi el método citado anteriormente, se obtuvieron dos fracciones que llamaremos: fracción "A" a la que resultó del filtrado después de haber agregado la Norita A, cuya acción no se indica en el presente trabajo por no haber sido estudiada, y la fracción $\mathrm{B}$ o sea la substancia eluída que uti- 
lizamos en los ensayos que reportaremos posteriormente; esta substancia se probó por los siguientes métodos: Copas de Oxford, De Beer-Sherwood y Waksman-Reilly.

Para probar el extracto se procedió en la siguiente forma: el extracto obtenido por purificación con Norita A, se dejó secar en un desecador con cloruro de calcio anhidro por espacio de una semana; una vez que estuvo seco, se recogió y se pesaron $140 \mathrm{mgr}$. que se disolvieron en alcohol al $10 \%$ formándose un precipitado amarillo lechoso en el caso de Naematoloma fasciculare y en el caso de Lycoperdon perlatum una solución ligeramente opalescente.

\section{Purificación con Filtro de Mandler}

Este método se siguió para purificar el extracto acuoso de Agaricus placomyces. La proporción del hongo empleada fué la misma que en el caso anterior. Todo el material que se usó fué estéril. La bujía se coloca en un cilindro de cristal y ambos a su vez se montan en un matraz de Xitasato y éste se conecta con una bomba de vacío, con objeto que el filtrado sea más rápido.

El material, limpio de tierra principalmente, se deja reposar en agua estéril durante 24 horas, con el objeto de que quede libre la mayor cantidad de sustancia antagónica; transcurrido este tiempo, se licúa el material y se procede a la filtración, recogiéndose el líquido filtrado en matraz estéril. El extracto obtenido de esta manera se probó por los mismos métodos que en el caso anterior: Copas de Oxford, de De Beer-Sherwood y Waksman-Reilly.

\section{Toxicidad en ratones}

También se trató de probar el grado de toxicidad que pudieran tener estos extractos, para lo cual se emplearon ratones blancos cuyo peso oscilapa entre $\operatorname{los} 26$ y $30 \mathrm{~g}$.

Se inyectaron extractos alcohólicos purificados. En este caso, del extracto seco se pesaron 80,60 y $40 \mathrm{mg}$. que se disolvieron en 0.3 c.c. de alcohol de $96^{\circ}$ y 0.7 c.c. de agua bidestilada estéril y después se inyectaron intraperitonealmente. Como el alcohol es tóxico aún a esta concentración, se inyectaron los ratones con extracto seco en alcohol al $10 \%$.

Los ratones se observaron frecuentemente durante dos o tres días, para saber si la substancia inyectable es tolerable o tóxica.

Se inyectaron también extractos acuosos crudos de los hongos, ya sea directamente, o después de haber sido filtrados por la bujía de Mandler. 


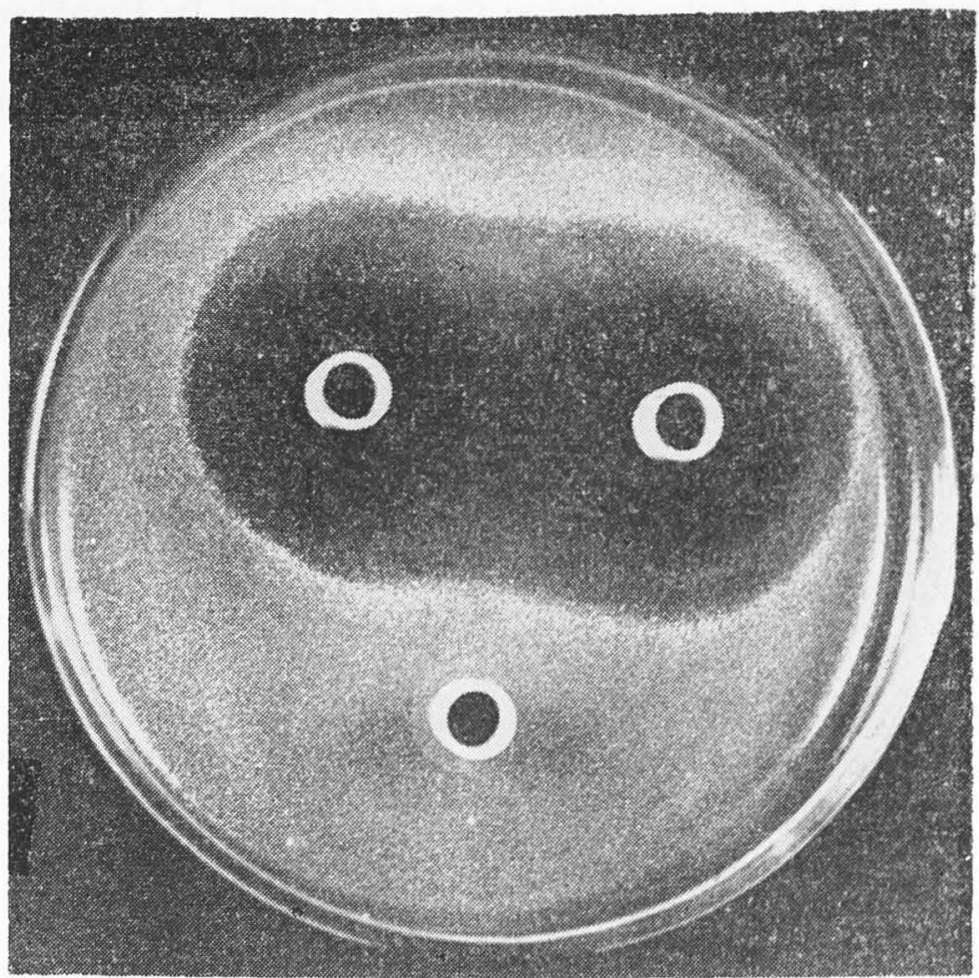

Formación tardía de los halos de inhibación de Agaricus placomyces por el método de las Copas de Oxford, contra la cepa Criptocuus neoformans var. inocuans, 8 días después de la incubación.

\section{Resumen}

Según los métodos seguidos se ve que de los 12 hongos empleados: Agaricus subrutilescens, Agaricus placomyces, Amanita caesarea, Boletus edulis, Clitocybe sp. (estípite blanco), Clitocybe sp. (estípite moreno), Collibya sp., Gomphus floccosus, Lactarius deliciosus, Lycoperdon perlatum. Melanoleuca vulgaris y Naematoloma fasciculare, únicamente este último y Agaricus placomyces son los de más importancia por inhibir a mayor" número de gérmenes. 
Solamente los extractos crudos en agua destilada, alcohol y acetona, o los purificados por filtración y con Norita A son los que presentan mayor actividad antibacteriana.

Se usaron gérmenes Gram positivos y Gram negativos comportándose estos últimos siempre resistentes a los extractos de Naematoloma fasciculare y Lycoperdon perlatum; en cambio, el extracto acuoso, tanto crudo como purificado de Agaricus placomyces, presenta una zona bastante amplia de inhibición hacia Escherichia coli, Figs. 4 y 5.

En Agaricus placomyces el halo que se forma es bastante grande, llegando a medir hasta $35 \mathrm{~mm}$. de diámetro en los extractos crudos; en los extractos purificados se obtienen como máximo zonas de inhibición de $25 \mathrm{~mm}$. de diámetro. Esta disminución se debe probablemente a que parte de la sustancia antagónica queda retenida en el residuo del filtrado o en el filtro mismo.

Las zonas de inhibición en todos los casos se forman después de transcurridas 18 a 24 horas de incubación y no se deforma el halo; en cambio, la formación del halo en el caso de Crytococcus neoformans var. inocuans, por el método de De Beer-Sherwood, se acentúa a medida que pasa el tiempo y su diámetro máximo se alcanza después de varios días. En esta misma cepa, probada por el método de las Copas de Oxford, después de 24 horas de incubación, no se forma halo, sino que éste se forma más tarde y alcanza su diámetro máximo aproximadamente en 8 días. Fig. 6 .

La acción antifúngica de Naematoloma fasciculare y de Lycoperdon perlatum es nula para los hongos patógenos de plantas. Los extractos de este hongo muestran escasa inhibición para la especie Nocardia asteroides. a la que inhiben a diferentes diluciones y la acción inhibidora del segundo es ligera para Epidermophyton floccosum, Microsporum canis, y Trichophyton tonsurans. El antagonismo de N. fasciculare hacia Cryptococcus neoformans var. inocuans es quizás el más importante, al igual que el obtenido por Agaricus placomyces.

La acción inhibidora de Agaricus placomyces es completamente nula para los hongos patógenos del hombre y de las plantas, excepto para Cryptococcus neoformans var. inocuans.

Por los resultados obtenidos con Agaricus placomyces, Naematoloma fasciculare y Lycoperdon perlatum, sería interesante continuar el estudio de los extractos de los hongos superiores.

Los extractos de Naematoloma y Lycoperdon son bastante tolerables, ya que $80 \mathrm{mg}$. de extracto seco y purificado, disueltos en alcohol al $10 \%$ e inyectados intraperitonealmente a ratones de $28 \mathrm{gr}$. de peso, son tolerados, no producen la muerte de los ratones, ni síntomas de intoxicación. Los extractos acuosos de $A$. placomyces también tienen un amplio margen de tolerancia. 
1.-De Beer E. J. \& M. B. Sherwood.-1945 A bactericidal action of antibiotic substances. Ind. Eng. Chem. Anal. Ed. 17, 556-558.

2.-Difco Manual Deshydrated culture media and reagents for microbiological and clinical laboratory procedures. 9a Ed. Detroit, Michigan, U.S.A.

3.-Fleming A.-1929 On the antimicrobial action of cultures of Penicillin with special reference to their use in the isolation of $H$. influenze. Brit. J. Exp. Path. XI, 226-236.

4.-Florey H. W. E. Chain et al.-1949 Antibiotics I, 3. Geoffrey Cumberlege. Oxford University Press. London, N. York, Toronto.

5.-Foster J. W. \& H. B. Woodruff.-1944 Microbial aspect of Penicillin. J. Bact. 47, 43-58.

6.-Gonçalves de Lima O., I. L. d'Albuquerque., P. Loureiro., L. de Albuquerque Araujo, A. Andrade.-1954 Selovicina, Novo Antibiótico isolado de Croton Se'owii Bail. An. Soc. Bio. Pernambuco XII, No I $27-31$.

7.-Gonçalves de Lima O., M. H. D. Maia., F. O. Falcon de Morais, M. P. Machado, M. G. Maciel, E. Silva.-1957 Antibiótico Antifungico Producido por Streptomyces (Cepa AM-154 IAUR) An. Soc. Bio. Pernambuco $X V$ Nọ I, 133-139.

8.-Gonçalves de Lima O., I. L. d'Albuquerque.-1958 Métodos Simples de Extractacao E. Purificao da Biflorina. Rev. Ins. Antib. Univ. Recife $I$ No I, 7-9.

9.-Herrel W. E.-1946 Penicillin and other antibiotic agents. 2-11. W. B. Saunders Company. Philadelphia and London.

10-Jackson W. F. \& H. B. Woodruf.-1953 Improvements in the cup assay of Penicillin. J. Biol. Chem. 48, 723.

11.-Lara C. L.-1949 Substancias Antibacterianas en vegetales. Tesis Profesional I.P.N.

12.-Márquez M. A., G. L. Guzmán, R. O. Cravioto y J. C. de la Torre.1950 Investigación de Actividades Antibióticas de Extractos de Plantas Superiores. Ciencia e Investigación VI, 471-476.

13.-Méndez P. M.-1953 Propiedades Antimicrobianas de Algunos Extractos de Plantas. Tesis Profesional I.P.N.

14.-Perrin H. L.-1949 El A B C de la Sulfonam:doterapia y la Antibioticoterapia 28-30 UTHEA México. 
15.-Ruiz J. \& R. Ibáñez.-1955 Métodos Biológicos de Valoración de Medicamentos. 389-391. $1^{\text {a }}$ Ed. Alhambra, S. A. Madrid.

16.-Salle A. J.-1956 Bacteriología General 508-512. $4^{\text {a }}$ Ed. Editorial Gustavo Gili, S. A. Barcelona.

17.-Sherwood M. B. E. A. Falco \& E. J. Beer.-1944 A rapid Method for the determination of Penicillin. Science 99, 247.

18.-Thomas S.-1930 Laboratory Manual in Bacteriology 148. Mc GrawHill Book Company, Inc. New-York.

19.-Waksman S. A.-1949 Microbial Antagonism and Antibiotic Substance. 146-1427. The Commonwealth Found. New-York.

20.-Winkins W. H.-1933 Investigation into the production of bacteriostatic substances by fungi (Preliminary examination of more of the larger Basidiomycetes and some of the larger Ascomycetes) Ann. App. Biol. 33, 188-190. 